\title{
6 Island disaster para-diplomacy in the commonwealth
}

\author{
Ilan Kelman, Megan Davies, Tom Mitchell, Iain Orr \\ and Bob Conrich
}

\section{ISLAND GOVERNANCE AND DISASTERS}

This chapter covers one particular aspect of the foreign relations of non-sovereign island jurisdictions (SNIJs), namely relations arising from disaster-related activities. Islands are among the territories most seriously affected by calamities, including the spectre of rising seas that may come with climate change. Yet non-sovereign islands are not so well equipped to speak and act effectively for themselves in the face of such threats. This may be true even within the governing structures in which these islands find themselves, but it is even more serious given the weaknesses that may exist in their capacity to speak to and act in the international community on disaster-related activities. This chapter explores this issue of 'disaster para-diplomacy' for nonsovereign island jurisdictions, drawing on the para-diplomacy work of Duchacek et al. (1988), Michelmann and Soldatos (1990), Soldatos (1993) and Lecours (2002), and adapting it to address the special circumstances of island disaster para-diplomacy where a SNIJ could interact with foreign governments and with international agencies.

For SNIJs, determining responsibility for pre-disaster actions, such as planning and mitigation, and post-disaster actions, such as response and recovery, is not always straightforward, even if legal responsibilities are clearly delineated. Where a SNIJ and its governing state's capital are far apart - geographically as well as in terms of communication, culture and/or cooperation - an event could affect the SNIJ without the national authorities realizing, or being willing to accept, the extent of the impact. Similarly, internationally or nationally mandated programmes related to disaster risk reduction (e.g. UNISDR, 2005, including national platforms for disaster-risk reduction) might be implemented inappropriately from the SNIJs' perspective because less attention is given to the SNIJs' needs compared with (typically much larger) national needs, as determined by and from the capital. Where perceived or real inadequacies arise in a state's disaster-related activities, a SNIJ has five principal options, some of them interconnected:

- Do nothing.

- Pursue full sovereignty or more autonomy from the state.

- Focus on improving the state's actions.

- Focus on improving the SNIJ's capabilities.

- Focus on dealing directly with international organizations and other governments. 
That a SNIJ has any options at all is a function of its jurisdictional power. However, its power is granted in the context of an overarching political architecture that will typically circumscribe bow and when it may use these political resources. This is particularly the case in the 'grey area' of para-diplomacy, where neither legal rules nor practice will tell us enough about what a sub-national island can do in representing itself to the outside world.

This chapter examines in some detail the fifth and last option in the above list: a sub-national island territory flexing its jurisdictional muscle in a direction that could be seen as threatening to or destabilizing of the balance of power with its governing state by engaging in inter-state relations which have typically been, and are often vigorously defended as, the exclusive preserve of sovereign states. The SNIJ does so in the context of disaster-related activities that may find the same governing state disposed to tolerate some flexibility and concede departures from the official rule book. But would these departures create precedents for other forays into international relations by the SNIJ, or other thus emboldened SNIJs?

This chapter's exploratory proposition is that there is some, but little current, evidence for island disaster para-diplomacy; yet scope exists for it to become more significant, so the matter should be addressed at the policy level. An overview of case studies is provided as illustrative of the legalities and realities which are evident when seeking island disaster para-diplomacy 'on the ground'. Case studies presented are from the Commonwealth because that geographic scope is The Round Table's main interest. The lessons are then discussed, leading to advice regarding the relevance of island disaster para-diplomacy to the Commonwealth. Thus the chapter does not consider SNIJs such as Hawai'i, Hainan, Sakhalin, Sardinia, Sicily, Corsica, Crete, and the French and Dutch territories; nor does it cover para-diplomacy in other areas such as trade negotiations, offshore finance, sport (e.g. the Island Games) and tourism.

\section{Disaster diplomacy and disaster para-diplomacy}

Kelman and Koukis (2000, p. 214) ask: "Do natural disasters induce international cooperation amongst countries that have traditionally been "enemies'?" Although the answer to this question has thus far been mainly negative (e.g. earthquakes in Greece and Turkey in 1999 (see Ker-Lindsay, 2000) or monitoring hurricanes which could hit both Cuba and the USA (Glantz, 2000)), these and other case studies, along with theoretical analyses on disaster diplomacy (see http:// www.disasterdiplomacy.org), suggest that disaster-related activities can catalyse but rarely create international cooperation amongst hostile partners (e.g. Kelman, 2003; 2005b; 2006a; Holloway, 2000; Rajagopalan, 2005; Waarner, 2005).

If disaster-related activities could positively improve relations among states which would not normally be prone to such cooperation, then a similar change could occur in the relations that SNIJs may have, or may not have had previously, with state governments which are not their governing state, or with international agencies. Disaster-related activities could then prove to be the catalyst to launch a SNIJ into international relations. 


\section{ISLAND DISASTER PARA-DIPLOMACY EXAMINED}

\section{Legalities}

Three legal regimes are examined regarding island disaster para-diplomacy: constitutions, disaster-related SNIJ legislation, and intergovernmental organizations. Illustrative examples from different regions of the world are provided as an overview.

\section{Constitutions}

A review of constitutions of Commonwealth states with SNIJs reveals limited mention of disaster-related activities (see Appendix 6.1). Where emergency powers are detailed, they tend to rest with either the head of state or the head of government or are split between the two roles, sometimes with provision to delegate authority in case the designated individuals are unable to assume these duties.

Four constitutions suggest connections between sub-national jurisdictions and disaster-related activities. South Africa's constitution's Schedule 4 states that 'disaster management' is a joint national-provincial responsibility, but no South African provinces are SNIJs. Clause 187E(4) of Papua New Guinea's constitution gives the National Executive Council the authority to suspend a provincial government or a local authority which cannot govern as the result of a disaster: in some ways pre-empting sub-national para-diplomacy because it gives the SNIJ less authority. Chapter XII, 114(2)(b) of the Solomon Islands' constitution states that parliament shall "consider the role of traditional chiefs in the provinces", which leaves a possibility for chief-based, disaster-related SNIJ roles. Chapter II, Section 19 of the St Kitts and Nevis constitution describes Nevis' responsibilities and powers regarding declarations of emergency. Nevis can declare or revoke states of emergency, but no mention is made of requesting international assistance.

The lack of mention in constitutions of SNIJs' disaster-related activities is not surprising, not only because constitutions are deemed to be documents covering an entire state, but also because an emergency is not normally a substantive area of jurisdiction for purposes of a constitutional division of powers. In practice, it would (at best) be a shared field in a federal arrangement, with the national government having the ever-present right to declare a national emergency (even if confined to only a part of the state), since it would presumably by then have become a matter of national interest and concern. Emergencies referred to here are national emergencies, even if and when affecting only part of the state. No state constitution expressly forbids a sub-national jurisdiction from undertaking disaster para-diplomacy. But, depending on the exact situation and judicial precedents, it would be possible to challenge before the courts any such action as violating the national government's responsibilities for national security, defence, foreign affairs or external borrowing (for example, regarding reconstruction loans).

In the case of the UK's island overseas territories the constitutions of Anguilla, Bermuda, the Cayman Islands, Montserrat, and the Turks and Caicos Islands (TCI) mention emergency procedures, but no other disaster-related activities. External affairs, however, is a power specifically reserved for each territory's governor (or 
equivalent), who is the British government's representative for each SNIJ (see also House of Commons, 2004). The constitutions therefore effectively preclude paradiplomacy from a legal perspective because any external affairs activities must be conducted with or through the governor (or equivalent), i.e. the British government. Nevertheless, as seen below, the matter is not that simple, since SNIJ action cannot be altogether excluded.

\section{Legislation}

Moving beyond constitutions to disaster-related SNIJ legislation in the Commonwealth, there is hardly any provision to call for international assistance. For example, paragraphs 12d, 21h and 22j of Tasmania's Emergency Services Act 1976 permit help to be requested from the Australian government or from another Australian state or territory, but other sources are not mentioned.

Both Canada's island, or mainly island, provinces - Newfoundland and Labrador (Emergency Measures Act 1990, amended 2004) and Prince Edward Island (Emergency Measures Act 1998) - have disaster-related legislation. Both SNIJs have signed the International Emergency Management Assistance Memorandum of Understanding (MOU) (18 July 2000) along with New England's states, Québec, Nova Scotia and New Brunswick. The MOU permits emergency-related training and assistance to be provided across the US-Canada border without directly involving the national governments. This is because the Canadian constitution, as interpreted by the courts, has left open a role for provinces in external relations, provided they act within their areas of jurisdiction. Disasterrelated, cross-border collaboration is relatively common at the sub-national level (e.g. Local Authorities Confronting Disasters and Emergencies, at www.ulai.org.il/ lacde.htm) but has not yet translated into legislation explicitly addressing paradiplomacy.

\section{Inter- or supra-governmental organizations}

In dealing with inter- or supra-governmental organizations, other examples of island disaster para-diplomacy are evident.

The Delegation of the European Commission in Barbados and the Eastern Caribbean (www.delbrb.cec.eu.int) is accredited to three UK overseas territories (UKOTs) - Anguilla, British Virgin Islands (BVI) and Montserrat - and deals with those SNIJ governments directly on some disaster-related activities. Montserrat has received millions of euros for reconstruction following the start of volcanic eruptions there in 1995, one example being $€ 2543000$ for a 'Montserrat Resettlement Project' in 2005 (Selected Projects, 2005). Anguilla received 'some funds' to repair road damage after Hurricane Lenny hit the island in 1999 (European Development Fund, 2006). Additionally, after Hurricane Ivan in 2004, the Cayman Islands were promised relief money from the European Commission in Brussels (Cayman Islands Government Information Service, 2006). The respective governors of these islands are involved in these projects to some extent; but their specific role in each case is not always clear, suggesting that island disaster paradiplomacy is happening to some degree between the European Commission and the UKOTs. 
In the Pacific the Delegation of the European Commission for the Pacific (www. delfji.cec.eu.int) deals with three Commonwealth SNIJs: Cook Islands, Niue and Pitcairn. On disaster-related activities, after Cyclone Heta hit Niue in 2004, €600 000 of previously committed funds was redirected to reconstruct the island's single hospital (Niue, 2006).

Again in the Caribbean, the Caribbean Disaster Emergency Response Agency (CDERA) is involved in disaster-related activities with its members through their national disaster management organizations. For example, the national organization of St Kitts and Nevis is the National Emergency Management Agency (NEMA). Despite lack of specific reference in the state's constitution, the Nevis Disaster Management Office (NDMO) exists. NEMA is mandated to control all international disaster matters and acts on behalf of both islands within CDERA. One of CDERA's roles is to provide an immediate and coordinated response to a disaster event once the affected state requests such support. In a disaster affecting a SNIJ only, such as Barbuda or Tobago, a request for CDERA assistance would have to be lodged through the SNIJ's governing state.

Four UK SNIJs are CDERA members: Anguilla, BVI, Montserrat and TCI. CDERA works through the national disaster management organizations, yielding examples of SNIJs dealing directly with a regional organization for disaster-related activities, although again with their respective governors' involvement to different degrees.

In the Pacific, two New Zealand SNIJs, Cook Islands and Niue, are members of the South Pacific Applied Geoscience Commission (SOPAC). Its Community Risk Program has the goal "to improve disaster risk management practices to build safer and more resilient communities" (www.sopac.org/tiki/tiki-index.php?page=Goal). As with CDERA, this interaction with SOPAC provides examples of Commonwealth SNIJs dealing with a regional organization for disaster-related activities.

Montserrat, the Cook Islands and Niue were each represented by delegations separate from each SNIJ's governing state's delegation at the UN World Conference on Disaster Reduction in Japan from 18 to 22 January 2005, run by the United Nations International Strategy for Disaster Reduction (UNISDR). As a follow-up to the World Conference on Disaster Reduction, as of March 2006, BVI and the Cayman Islands were the only sub-national jurisdictions to have provided UNISDR with a National Report on the Implementation of the Hyogo Framework for Action (see www.unisdr.org/eng/hfa/hf-implemt-states.htm). ${ }^{1}$ Also, as of March 2006, Montserrat and BVI are the only sub-national jurisdictions listed by UNISDR as providing country-related disaster information (www.unisdr.org/eng/country-inform/ introduction.html). Island disaster para-diplomacy is occurring through the UN system.

The Alliance of Small Island States (AOSIS) is another intergovernmental organization with SNIJ members: the Cook Islands and Niue. AOSIS "functions primarily as an ad hoc lobby and negotiating voice for small island developing states (SIDS) within the United Nations system" on global climate change issues (www.sidsnet.org/ aosis). As these creeping environmental changes (e.g. Glantz, 1999; 2003) begin to affect SNIJs more, and perhaps to a greater extent than the SNIJs' governing states, SNIJs could take to the international stage to try to address these issues, thereby effecting disaster para-diplomacy. Sea-level rise and salinification of water resources are strong candidates for precipitating such efforts because they have the potential to threaten a SNIJ's very existence. 
Examining these three different sets of legal regimes provides scattered evidence of island disaster para-diplomacy in the Commonwealth. Despite the relatively weak legal basis for SNIJs to engage in disaster para-diplomacy in the Commonwealth, there are various examples of sanctioned initiatives. They include having disaster-related agencies at SNIJ level partaking in regional or international disaster-related forums; disaster management coordination among substate actors of different states; and receiving international funds to mitigate disaster effects.

\section{Realities}

The absence of legal sanction, however, may not constitute so strong a barrier against action. In fact, SNIJs frequently provide examples where de jure principles are tweaked by de facto practices. The presence of some degree of sanctioned local autonomy, coupled with physical distance from the governing state, provides a vehicle for challenging, deliberately or inadvertently, the current regime of mainland-island relations. In addition to legal principles, the realities of a SNIJ's situation could influence whether or not disaster para-diplomacy occurs.

Tristan da Cunha, home to some 300 people, is the remotest inhabited island in the world and is a dependency of the UK overseas territory of St Helena. On 21 May 2001, hurricane-force winds caused extensive damage to Tristan's sole settlement. Despite damage worth at least several hundred thousand pounds (Brock, 2005; Brock and Glass, 2005; Glass, 2003), the UK government only donated $£ 75000$ (Banking News, 2001). Meanwhile, an international appeal was sent out through expatriate Tristanians who, within a few months, raised $£ 79936.08$ for a Disaster Fund (personal communication from Colin Topping, 27 November 2001, quoting a letter he received from Tristan da Cunha's Chief Islander). The remainder was covered by subsequent international donations as well by the Tristanians, including their volunteer labour for the repairs. The majority of materials were ordered and shipped from Cape Town, South Africa.

A situation existed where, according to the Tristanians, the UK government was not providing Tristan da Cunha with all the needed post-disaster support. Tristanians solicited funds from elsewhere, setting up a disaster fund for this purpose. They could also have approached non-UK state governments or international agencies for post-disaster supplies and for implementing mitigation. Tristanians, though, are highly loyal to the UK. One of the authors (Conrich) visited Tristan da Cunha in January 2002 and found a resigned acceptance of the limitations of the UK government's reconstruction and development assistance, with no impetus towards considering looking elsewhere. Another important factor contributing to this acceptance was the islanders' wish not to be considered beggars, and their own strong sense of self-reliance. To use para-diplomacy to find other sources of support also entailed opposing the UK government's representative on the island, an idea foreign to Tristanian culture. Yet the disaster fund allowed international donors (state and non-state) the opportunity to support the rehabilitation effort on Tristan directly, hence bypassing the UK government.

Hurricane Ivan struck the Cayman Islands in September 2004. Timothy Adam, the Chief Executive of Cable and Wireless (Cayman Islands), suggested that one of the islands, Grand Cayman, needed outside help: "Grand Cayman urgently needs 
military intervention to restore and to preserve law and order" (Adam, 2004a). Adam requested US military intervention because "the police are very limited in number and they are exhausted yet reports are that the British have refused to send in Royal Marines or Military Police to help". Nine days later Adam (2004b) noted that his original letter was not intended for publication and represented himself, not his company. However, he added:

the local officials in the Cayman Islands are doing an outstanding job, considering the extent of the storm damage and the resources they have... they're not sitting there helpless waiting for outside assistance, but frankly I believe they are less inclined to ask for help or expect any rapid assistance especially from Britain given their experiences over the past week.

American help did not arrive; but this example illustrates a SNIJ-based suggestion of external governmental assistance when the governing state did not fulfil requests for help.

Following the 26 December 2004 Indian Ocean tsunamis, the Andaman and Nicobar Islands, a SNIJ of India, suffered 1395 people killed, 1514 people injured, and 40542 people displaced (Andaman and Nicobar Administration, 2005). India's government waived paperwork restrictions on tsunami-related foreign contributions for affected regions in India, including the Andaman and Nicobar islands (Government of India, 2004). Normally, any organization receiving foreign funds must register with India's government or obtain prior permission to accept funds. Tsunami-related donations were exempted. This decision acknowledged that, for efficient disaster response, money could go directly to the SNIJ's government. The Andaman and Nicobar Islands Administration has the capability to manage aspects of crises, which includes dealing with state governments other than its governing state and with international agencies to gain post-disaster aid.

The Caribbean Association of Electric Utilities and Energy Service Providers (CARILEC) has created a disaster fund into which members contribute. After an affected member utility requests assistance in restoring a damaged electricity grid, the fund pays for emergency teams from other member utilities to assist. One CARILEC member is BVI Electricity Corporation, whose sole shareholder is BVI's government. When this company requests post-disaster assistance from CARILEC, a form of paradiplomacy is occurring, involving a regional agency and a SNIJ government represented through a public utility.

The small islands of Tikopia and Anuta are located in the far eastern Solomon Islands. Officially part of Temotu province, the islands lack airstrips, jetties and reliable off-island communication. Governance is undertaken by the island chiefs who, as noted earlier for the Solomon Islands, have constitutional recognition. On 28 December 2002 the islands were hit by Category 5 Cyclone Zoë (Anderson-Berry et al., 2003; Kelman, 2005a; Vettori and Stuart, 2004; Yates and Anderson-Berry, 2004). None of the inhabitants perished, but the devastation made their food, water and shelter situation dire.

The first formal aid supplies arrived by ship from Honiara, the Solomon Islands' capital, despite the distance of more than $1000 \mathrm{~km}$ plus logistical and political delays. However, the closest location to Tikopia and Anuta from which relief supplies could have been brought is in Vanuatu, with Luganville being just $400 \mathrm{~km}$ away from 
Tikopia. This possibility was demonstrated by journalist Geoff Mackley, who flew relief supplies to Tikopia from Vanuatu by helicopter (The Australian, 2003).

In principle, thanks to the constitutional clause quoted earlier, the chiefs might have been able to request assistance by boat or helicopter from Vanuatu, albeit as a short-term measure. In practice, Tikopia and Anuta had only one radio each and both had been broken before Cyclone Zoë, being made operational only after a post-cyclone aid team had arrived (Anderson-Berry et al., 2003). In addition, such action could have had diplomatic implications. First, Honiara could have lost face because Vanuatu would have helped Solomon Islanders (instead of, or before, the Solomon Islands government). Second, aid supplies crossing state lines normally have to be approved by the recipient state, so if that protocol were followed, Honiara would have had to actively accept help from Vanuatu. Third, with the residents of Tikopia and Anuta being ethnically more closely related to the people of Vanuatu than to those in the western part of the Solomon Islands, the Honiara government might have interpreted Vanuatu's assistance as fuelling conflict within the Solomon Islands.

Nevertheless, islanders in a post-disaster situation would presumably be more interested in obtaining relief supplies and rebuilding their communities as soon as possible wherever the help arrived from, rather than being intent on playing paradiplomacy games. This is important because the opportunities presented for paradiplomacy by disaster-related activities are at the same time circumscribed by pragmatism. A governing state may tolerate, absolve, or sanction para-diplomatic initiatives by any of its SNIJs in the interests of expediency, such as faster provision of supplies or facilitated evacuation. The SNIJ may do likewise for similar purposes, rather than as a strategic choice. Disasters are often short-sightedly seen as rare 'oneoff' events, even though successful disaster risk reduction is a long-term endeavour and needs to be integrated into development and sustainability processes (Lewis, 1999; Mileti et al., 1999; Wisner et al., 2004). Where the short-term view prevails for a disaster event, expectations could be made regarding the relationship between the $\mathrm{SNIJ}$ and its governing state, even though such temporary approaches could harm disaster para-diplomacy in the long term, as shown for disaster diplomacy cases (Kelman, 2003; 2006a; Ker-Lindsay, 2000).

\section{DISCUSSION}

The evidence and cases drawn from Commonwealth SNIJs suggest that island disaster para-diplomacy has so far occurred infrequently in practice. In law no official documents or mechanisms were found which provided explicit permission for Commonwealth SNIJs to engage in para-diplomacy for specific, disaster-related activities, even though disaster risk reduction is best achieved at the local level with community involvement (e.g. Lewis, 1999; Twigg, 1999; Wisner et al., 2004). Where the power to request external assistance for disaster-related activities, usually emergencies, is prescribed by law, such 'external assistance' normally refers to a higher jurisdiction within the governing state, such as a provincial or national government. The power to call for disaster-related international assistance generally rests with the governing state. Examples of SNIJs bypassing that legal authority were rarely evident, although opportunities were not lacking. 
Where a SNIJ is geographically distant from its governing state - making disasterrelated logistics from this source more difficult, more expensive and slower to obtain - is para-diplomacy more likely? After all, if a governing state does not provide sufficient disaster-related support, and sufficiently quickly, for a SNIJ, as in the cases of Tristan da Cunha (see above) and Montserrat (Clay, 1999; Davison, 2003; Mitchell, 2006; Pattullo, 2000), then the SNIJ might be forced to look elsewhere, even if logistic difficulties increase and even if the governing state considers such action to be illegal (which would need to be tested in court). In such a situation, an option to avoid bypassing the governing state would be using the media to embarrass the governing state into acting more appropriately. Rather than para-diplomacy, the media option was exercised for Tristan da Cunha following the 1961 volcanic eruption there which led to the island's evacuation (de Boer and Sanders, 2002).

Even where para-diplomacy might alleviate the situation, as in cases requiring evacuation where the nearest population centre to a SNIJ does not belong to its governing state, para-diplomacy is not necessarily enacted. Additionally, island paradiplomacy occurs for many non-disaster activities - including sport, culture, trade, and tourism (Baldacchino, 2004; 2006) - irrespective of any logistical constraints and, at times, legalities. Indeed, SNIJ para-diplomacy is far more present for nondisaster-related acts than for disaster-related ones.

Two other reasons might explain why Commonwealth SNIJs have not yet much exploited disaster para-diplomacy. First, many SNIJs have a limited interest in seeking sovereignty, as long as they continue to enjoy domestic law-making authority that cannot be challenged by the central government (Baldacchino, 2004; 2006). One advantage is the 'umbilical cord' to a larger entity, the governing state, which would then be officially responsible for the SNIJ during crises (Baldacchino, 2004; McElroy and Mahoney, 2000). Although this responsibility might not always be acted upon, or might not be acted upon with the required speed or to the required extent (as shown by some of the examples in this chapter), the connection to the governing state provides a psychological crutch which, in times of need, is hopefully transformed into a physical crutch, especially through disaster response and reconstruction resources. The crutch could fuel the view that external assistance is always at hand, hence local preparation is unnecessary: a 'handout mentality' identified for many islands (Tuiloma-Palesoo, 2004). Actively pursuing disaster para-diplomacy could push SNIJs towards greater autonomy, threatening the availability and disposition of the governing state to provide disaster-related support. However, to succeed, such initiatives would need to be entertained as part of long-term relationship building (that is, para-diplomacy proper), which should not be tied down to one specific disastrous event.

Second, similarly to many sovereign governments, SNIJs and their governing states do not always pay sufficient attention to disaster-related activities until the issue is forced upon them, often by a dramatic event. The volcanic threat to Montserrat was documented scientifically, and the information was communicated to both Montserratian and British authorities (e.g. Wadge and Isaacs, 1987; 1988) but little action was taken until the volcano erupted (Mitchell, 2006). As Kelman (2006b) describes, the threat of Indian Ocean tsunamis was well documented and efforts had been made for at least 30 years to garner support for warning systems, but other activities were deemed to be a higher priority until over 250000 people were killed by 
tsunamis on 26 December 2004. An Indian Ocean tsunami warning system has since been started. Disaster para-diplomacy is not pursued by SNIJs partly because disasterrelated activities are not a high priority for the SNIJ or for its governing state.

Overall, these reasons suggest that Keating's (1999) para-diplomacy motivators economic, cultural and political - exclude disaster-related activities; however, a disaster event could nonetheless harbour political capital. A SNIJ's government or political grouping could exploit a disaster situation to promote its views about sovereignty. Successful disaster para-diplomacy, such as using external assistance for effective mitigation or reconstruction, could provide evidence of SNIJ government efficacy and thus garner support for sovereignty among the locals. In contrast, continued reliance on external assistance, particularly from or managed by the SNIJ's governing state, could illustrate the need and logic for persisting dependency, garnering support for those islanders who oppose outright sovereignty. The poor response following the 1970 cyclone in East Pakistan contributed towards a subsequent revolt that led to the creation of Bangladesh (Lewis, 1999). However, the initially inadequate response from the UK government to the volcanic eruptions on Montserrat did not promote a push for sovereignty there (Fergus, 2002).

In linking autonomy concerns with disaster para-diplomacy, balance of interests is a factor deserving of analysis. This compares the disaster-related interests of the SNIJ with those of its governing state. Balance of interests does not indicate directly whether increased autonomy would be promoted or inhibited by a SNIJ's disaster-related activities. It provides a baseline for dialogue on disaster-related activities between a SNIJ and its governing state by indicating each party's starting point for this topic. Acceptance of similarities and differences can assist in building trust and in tackling disaster-related issues properly, possibly influencing a SNIJ's direction towards or away from increased autonomy. Yet the autonomy-related decisions of a SNIJ or its governing state are not necessarily based on practicalities such as balance of interests, needs, or the population's desires. Nationalism or a governing state's wish to get rid of a 'liability' could be a key driver nudging a SNIJ towards sovereignty - what has been called "upside down decolonization" (Hoefte and Oostindie, 1989) - and a specific response (or non-response) regarding disaster-related activities may be part of a governing state's and/or a SNIJ's wider plan regarding the SNIJ's future.

\section{CONCLUSION}

This chapter supports the conclusion drawn by Kelman and Koukis (2000) that a disaster could significantly spur a diplomatic process which had another basis, but that a disaster per se is unlikely to generate new diplomacy. Disaster-related activities can catalyse, but do not create, or sustain cooperation.

There are, however, 'windows of need' which present opportunities for pragmatism in the context of disasters. Para-diplomacy has been an option in such situations; but rarely has this option been adopted and such powers usurped. Moreover, a disaster event might not be the best situation to entertain para-diplomacy, since the latter is essentially a sustained, cultivated and groomed long-term relationship with significant state and non-state actors, as disaster-related activities ought to be. Regrettably this is not always so with decisions made during and immediately following disaster events. 
Given the impact of disasters on SNIJs and the strong link of disaster-related activities to development, sustainable livelihoods and environmental management (e.g. Lewis, 1999; Mileti et al., 1999; Wisner et al., 2004), there is no obvious reason for disaster-related activities to be outside the purview of para-diplomacy. Moreover, a disaster could present an opportunity to the politically resourceful. Both pro- and anti-sovereignty movements in a SNIJ could use disaster para-diplomacy or the lack thereof to support broader political goals, irrespective of legal coda.

Finally, the comparison by Sims (2000) of the Commonwealth with the International Court of Justice for the purpose of solving disputes is pertinent. With disaster-related activities increasingly becoming a human rights concern (e.g. Kent, 2001; Radix Network, at www.radixonline.org), could a Commonwealth SNIJ request adjudication on its governing state's allegedly inadequate disaster-related actions? Could the Commonwealth be asked to judge, or would it be ignored and bypassed, with these concerns taken elsewhere? Should the Commonwealth, as a global organization, promote itself as a first or last resort for such disputes? Some precautionary preparation and planning appear timely.

\section{Note}

1. As of March 2006 the Cayman Islands' report was from November 2005 and comprises 19 tables for action, of which 16 tables were blank. BVI's report (undated) was two pages long, listing disaster-related project titles, timeframes and contact points.

\section{References}

Adam, T. (2004a) Urgent US military intervention needed in Grand Cayman, Cayman Net News Online, at http://caymannetnews.com/2004/09/738/letter.shtml

Adam, T. (2004b) Cable \& Wireless Chief Executive clarifies his personal position, Cayman Net News Online, at http://www.caymannetnews.com/2004/09/738/letter.shtml

Andaman and Nicobar Administration (2005) Damages Due to Tsunami, Daily Report Dated 15th February, Port Blair, Andaman Islands: Ministry of Home Affairs (NDM Division), Andaman and Nicobar Administration.

Anderson-Berry, L., Iroi, C. and Rangi, A. (2003) Tropical Cyclone Zoë, Tikopia and Anuta, Solomon Islands, December 26-29, 2002 (Townsville: Centre for Disaster Studies, James Cook University).

The Australian (2003) Islanders' miracle survival, 4 January.

Baldacchino, G. (2004) Autonomous but not sovereign? A review of island sub-nationalism, Canadian Review of Studies in Nationalism, XXXI(1-2), pp. 77-91.

Baldacchino, G. (2006) Innovative development strategies from sub-national island jurisdictions? A global review of economic policy and governance practices, World Development, 34(5), pp. 852-867.

Banking News (2001) Tristan da Cunha - disaster relief fund, Press release, Crown Agents Financial Services, 25 June, at http://www.crownagents.com/news/news.asp?step $=4 \&$ NewsID $=199$.

Brock, J. (2005) Tristan da Cunha: flags half-mast for tsunami victims, Tristan Times, 5 January.

Brock, J. and Glass, S. (2005) Tristan: poaching threatens Tristan da Cunha's hurricane recovery, Tristan Times, 12 June.

Cayman Islands Government Information Service (2006) Top FCO official pledges more Cayman support, Press release, Cayman Islands Government Information Service. 
Clay, E. (1999) An Evaluation of HMG's Response to the Montserrat Volcanic Emergency, DFID Evaluation Report EV635 (London: DFID).

Davison, P. (2003) Volcano in Paradise (London: Methuen).

De Boer, J. Z. and Sanders, D. T. (2002) Volcanoes in Human History (Princeton, NJ: Princeton University Press).

Duchacek, I. D., Latouch, D. and Stevenson, G. (Eds) (1988) Perforated Sovereignties and International Relations: Trans-Sovereign Contacts of Sub-national Governments (Westport, CT: Greenwood Press).

European Development Fund (2006) Delegation of the European Commission in Barbados and Eastern Caribbean, at www.delbrb.cec.eu.int/en/eu_and_country/oct_ anguilla_development.htm

Fergus, H. (2002) Constitutional modernisation in Montserrat and the Cayman Islands: taking the British seriously? Paper presented at the Montserrat Country Conference, 1314 November, Montserrat.

Glantz, M. H. (Ed.) (1999) Creeping Environmental Problems and Sustainable Development in the Aral Sea Basin (Cambridge: Cambridge University Press).

Glantz, M. H. (2000) Climate-related disaster diplomacy: a US-Cuban case study, Cambridge Review of International Affairs, XIV(1), pp. 233-253.

Glantz, M. H. (2003) Climate Affairs: A Primer (Covelo, CA: Island Press).

Glass, J. (2003) Tristan: official hurricane report, Tristan Times, 17 November.

Government of India (2004) Order and Press Release, document II/21022/11(19)/2004-FCRA I (New Delhi: Government of India, Ministry of Home Affairs, Foreigners Division).

Hoefte, R. and Oostindie, G. (1989) Upside down decolonization, Hemisphere, 1(2), pp. 2831.

Holloway, A. (2000) Drought emergency, yes ... drought disaster, no: southern Africa 199193, Cambridge Review of International Affairs, XIV(1), pp. 254-276.

House of Commons (2004) Written Answers to Questions [8 November], Foreign and Commonwealth Affairs, United Kingdom Overseas Territories, Hansard (House of Commons Daily Debates), 426, Part No. 51, Column 515W.

Keating, M. (1999) Regions and international affairs: motives, opportunities and strategies, in F. Aldecoa and M. Keating (Eds), Paradiplomacy in Action: The Foreign Relations of Subnational Governments, pp. 1-16 (London: Frank Cass).

Kelman, I. (2003) Beyond disaster, beyond diplomacy, in M. Pelling (Ed.), Natural Disasters and Development in a Globalizing World, pp. 110-123 (London: Routledge).

Kelman, I. (2005a) Some outlying effects of Cyclone Zoë, in Tudor Rose Publications \& International Strategy for Disaster Reduction (eds) Know Risk, p. 237 (Leicester and Geneva: Tudor Rose Publications and the International Strategy for Disaster Reduction).

Kelman, I. (2005b) Tsunami diplomacy: will the 26 December, 2004 tsunamis bring peace to the affected countries?, Sociological Research Online, 10(1), at http:// www.socresonline.org.uk/10/1/kelman.html

Kelman, I. (2006a) Acting on disaster diplomacy, Columbia Journal of International Affairs, 59(2), pp. 215-240.

Kelman, I. (2006b) Warning for the 26 December 2004 tsunamis, Disaster Prevention and Management, 15(1), pp. 178-189.

Kelman, I. and Koukis, T. (Eds) (2000) Disaster diplomacy, Special section, Cambridge Review of International Affairs, XIV(1), pp. 214-294.

Kent, G. (2001) The human right to disaster mitigation and relief, Environmental Hazards, 3 , pp. 137-138.

Ker-Lindsay, J. (2000) Greek-Turkish rapprochement: the impact of 'disaster diplomacy'?, Cambridge Review of International Affairs, XIV(1), pp. 215-232.

Lecours, A. (2002) Paradiplomacy: reflections on the foreign policy and international relations of regions, International Negotiation, 7, pp. 91-114. 
Lewis, J. (1999) Development in Disaster-prone Places: Studies of Vulnerability (London: Intermediate Technology Publications).

McElroy, J. L. and Mahoney, M. (2000) The propensity for political dependence in small island microstates, Insula: International Journal of Island Affairs, 9(1), pp. 32-35.

Michelmann, H. J. and Soldatos, P. (1990) Federalism and International Relations: The Role of Subnational Units (Oxford: Clarendon).

Mileti, D. and 136 contributing authors (1999) Disasters by Design: A Reassessment of Natural Hazards in the United States (Washington, DC: Joseph Henry Press).

Mitchell, T. (2006) Building a disaster resilient future: lessons from participatory research on $\mathrm{St}$ Kitts and Montserrat, $\mathrm{PhD}$ thesis, Department of Geography, University College London.

Niue (2006) Online article from the Delegation of the European Commission for the Pacific, at http://www.delfji.cec.eu.int/en/achievements/niue.htm

Pattullo, P. (2000) Fire from the Mountain: The Tragedy of Montserrat and the Betrayal of its People (London: Constable and Robinson).

Rajagopalan, S. (2005) Post-tsunami international relations: a sea change?, Chaitanya Brief, 1(2), Chennai: Chaitanya Consult.

Selected Projects (2005) Delegation of the European Commission in Barbados and the Eastern Caribbean e-Newsletter, 11, pp. 17-18.

Sims, N. A. (2000) The Commonwealth and the International Court of Justice, The Round Table, 354, pp. 205-230.

Soldatos, P. (1993) Cascading subnational paradiplomacy in an interdependent and transnational world, in D. M. Brown and E. H. Fry (Eds), States and Provinces in the International Economy, pp. 45-64 (Berkeley, CA: Institute of Governmental Studies).

Tuiloma-Palesoo, D. (2004) Handout mentality, Small Islands Voice Global Forum, 16 November, at http://www.sivglobal.org/?read $=82$.

Twigg, J. (1999) The Age of Accountability? Future community involvement in disaster reduction, Australian Journal of Emergency Management, 14(4), pp. 51-58.

UNISDR (2005) Hyogo Framework for Action 2005-2015: Building the Resilience of Nations and Communities to Disasters (Geneva: UNISDR).

Vettori, L. and Stuart, C. (2004) Cyclone in the Pacific, Oxfam News (Australia), Autumn, pp. 10-11.

Waarner, M. (2005) Shaken, not stirred: Iranian foreign policy and domestic disaster, Master's thesis, University of Amsterdam.

Wadge, G. and Isaacs, M. C. (1987) Volcanic Hazards from the Soufrière Hills Volcano, Montserrat West Indies: A Report to the Government of Montserrat and the Pan Caribbean Disaster Preparedness and Prevention Project (Reading: Department of Geography, University of Reading).

Wadge, G. and Isaacs, M. C. (1988) Mapping the volcanic hazards from Soufrière Hills Volcano, Montserrat, West Indies using an image processor, Journal of the Geological Society of London, 145, pp. 541-555.

Wisner, B., Blaikie, P., Cannon, T. and Davis, I. (2004) At Risk: Natural Hazards, People's Vulnerability and Disasters (London: Routledge).

Yates, L. and Anderson-Berry, L. (2004) The societal and environmental impacts of Cyclone Zoë and the effectiveness of the tropical cyclone warning systems in Tikopia and Anuta, Solomon Islands, December 26-29, 2002, Australian Journal of Emergency Management, $19(1)$, pp. $16-20$. 


\section{Appendix 6.1}

\section{Disaster-related Activities in the Constitutions of Commonwealth States with SNIJs}

The UK and its SNIJs Guernsey, Jersey and the Isle of Man do not have written constitutions. Constitutional matters are interpreted based on common law and constitutionally related legal documents such as the Magna Carta. The UK's island overseas territories have constitutions, the disaster-related activities of which are mentioned in the paper's text.

Constitutions with minimal mention of disaster-related activities:

- India's constitution's Article 83 permits the sitting of parliament to be extended beyond five years if a Proclamation of Emergency is in operation.

- New Zealand's constitution does not mention disaster-related activities, nor do the Cook Islands' and Niue's constitutions. Paragraph 6(5)(iv) of Tokelau's constitution states that, when the general parliament is not in session, a council will be formed to run government, of which one duty is to "respond to national emergencies".

- Tanzania's constitution's First Schedule notes that 'emergency powers' are a Union Matter, i.e. for the state, not for any sub-national jurisdictions, including Zanzibar.

- Tonga's constitution's paragraph 19(a)(ii) permits government expenditure without the prior vote of the Legislative Assembly "In cases of war or rebellion or dangerous epidemic or a similar emergency", although the Legislative Assembly must be informed immediately.

Constitutions which detail powers to declare, and act during, a state of emergency with no further discussion of disaster-related activities:

- Antigua and Barbuda

- Bahamas

- Fiji

- Kiribati

- Malaysia

- Malta

- Maldives

- Mauritius
- Mozambique

- St Kitts and Nevis

- St Vincent and the Grenadines

- Samoa

- Seychelles

- Solomon Islands

- Trinidad and Tobago

- Vanuatu

Constitutions which detail powers to declare, and act during, a state of emergency with further mention of disaster-related activities:

- Papua New Guinea's constitution's Paragraph 202 states "The functions of the Defence Force are ... (c) to provide assistance to civilian authorities - (i) in a civil disaster; or (ii) in the restoration of public order and security on being called out in accordance with Section 204 (call-out in aid to the civil power)".

- South Africa's constitution's Schedule 4 states that "functional areas of concurrent national and provincial legislative competence' include 'disaster management", but none of the provinces are SNIJs.

- Tuvalu's constitution includes a subsidiary section in which the prime minister is assigned responsibility for disaster preparedness. 